REMATIE DIE MUALES

Campinas-SP, v.39, n.2, pp. 586-6o9, jul./dez. 2019

\title{
GENEALOGIAS DA ESCRITA EM LOS DIARIOS DE EMILIO RENZI. AÑOS DE FORMACIÓN
}

\author{
GENEALOGIES OF WRITING IN LOS DIARIOS DE \\ EMILIO RENZI. AÑOS DE FORMACIÓN
}

\author{
Miriam Viviana Gárate
}

\begin{abstract}
Resumo: $\mathrm{O}$ ensaio propõe a leitura de três ficções de origem em Los diarios de Emilio Renzi. Años de formación (2015): a primeira delas, vinculada à linhagem familiar (trata-se de explorar o livro a partir de algumas premissas expressas por Piglia em Ideologia y ficción en Borges); a segunda, relativa ao gênero diário enquanto genealogia da escrita "por vir"; em terceiro lugar, a ficção que põe em cena algumas leituras de formação, tendo em vista a genealogia do escritor de formas breves e a passagem para as formas de maior extensão. Palavras-chave: Ricardo Piglia, Diários, ficções de origem.
\end{abstract}

Abstract: The essay proposes a reading of three fictions of origin in Los diarios Emilio Renzi. Años de formación (2015): the first one is linked to the lineage of the family (that is the exploration of some premises expressed by Piglia in Ideología y ficción en Borges); the second is concerning to the genre diary as a genealogy of writing "for coming"; and the third one is a fiction that shows/stages some readings of formation in the perspective of a genealogy of the writer of brief forms and the passage to those of larger extension. Keywords: Ricardo Piglia, Diaries, Original Fictions.

O presente ensaio propõe uma aproximação a três ficções de origem imbricadas, legíveis no primeiro dos Diarios de Emilio Renzi (Años de formación), publicado por Ricardo Piglia em 2015, ao qual sucederam o segundo volume (Los años felices, de 2016) e o terceiro (Un día en la vida, de 2017). A primeira delas vinculada à linhagem familiar, ficção mediante a qual se narram as condições de acesso à escrita e algumas de suas

1 Instituto de Estudos da Linguagem (IEL) - Unicamp: <mvivianagarate@gmail.com>. 
propriedades. Em segundo lugar, a relativa ao gênero diário enquanto mito de origem da escrita "por vir" (futuro do passado que se refaz no presente da leitura, edição e reescrita dos cadernos). Por fim, a ficção que põe em cena algumas leituras de formação e o laboratório do escritor, por meio de um conjunto de nomes (uma estirpe literária) e de traços sublinhados na literatura dos precursores, tendo em vista a genealogia do escritor de formas breves - predominante no primeiro dos Diarios (cuja conclusão coincide com a publicação da coletânea de contos La invasión, em 1967) e a passagem para as formas de maior extensão (nouvelle e romance), que marcariam Los años felices e Los años de la Peste (primeira subsecção de Un día en la vida).

Os leitores dos Diarios de Emilio Renzi sabem que uma aproximação dessa ordem (que a proposição de uma ordem cronológica mais ou menos linear ou mesmo linearmente retrospectiva como estratégia de leitura) não faz justiça à temporalidade densa e ziguezagueante dos Diarios e que a cronologia de base, por assim dizer, desse primeiro volume - cujas secções diarísticas abarcam o período 1957-1967 - sofre permanentemente a interferência da leitura/reescrita e edição dos cadernos correspondentes a esses anos, da montagem e intercalação de textosautônomos, parcialmente reformulados (ou não), inéditos, semi-inéditos ou já publicados. Esse conjunto heteróclito é por sua vez emoldurado por dois relatos - ou melhor ainda, pela relação de dois diálogos implícitos intensamente evocativos, mas ancorados no presente da enunciação (escrita) do livro que se lê: "En el umbral", "Canto rodado". ${ }^{2}$ Trata-se, portanto, de uma justaposição de camadas temporais heterogêneas, irredutíveis a qualquer ordem ou desenho. Entretanto, para evitar um extravio de saída no

2 Transcrevo a seguir o índice de Anos de formação, publicado pela editora Todavia em 2017, com tradução de Sérgio Molina. No sucessivo, as citações no corpo do ensaio serão feitas no original espanhol e a tradução para o português constará em nota de rodapé. Anos de formação. Os diários de Emilio Renzi: Nota do autor. I: 1. Na soleira; 2. Primeiro diário (1957-1958); 3. Primeiro amor; 4. Segundo diário (1959-1960); 5. Uma visita; 6. Diário 1960; 7. No bar El Rayo; 8. Diário de um conto (1961). II: 9. No estúdio; 10. Diário 1963; 11. Os diários de Pavese; 12. Diário 1964; 13. O nadador; 14. Diário 1965; 15. Hotel Almagro; 16. Diário 1966; 17. A moeda grega; 18. Diário 1967; 19. Quem diz eu?; 20. Seixo rodado. Ao longo deste ensaio, as citações no corpo do texto serão feitas no original espanhol, e a respectiva tradução para o português constará em nota de rodapé. Para um exame pormenorizado dessa peculiar organização textual e das condições nas quais Ricardo Piglia empreendeu a escrita dos Diarios, já acometido pela doença que o mataria em janeiro de 2017, cf. o artigo de Teresa Orecchia-Havas (2019), em especial o primeiro item: "Lo póstumo, lo inédito. Una nota sobre edición, estética y poética”. 
labirinto, proponho simular provisionalmente que o tempo revisitado no primeiro dos Diarios é este: 1957-1967. Isso, não obstante que, de saída, a leitura convoque tempos/textos outros para se aproximar dessas ficções genealógicas - um modo de tentar fazer justiça, ou de escutar, aquilo que os Diarios dizem do tempo, ao esboçar e desestruturar (embaralhar) diversas ordens: a dos dias, a das séries temáticas, a dos gêneros.

O núcleo familiar como ficção de origem é uma tópica recorrente tanto na ficção (crítica) como na crítica (ficcional) de Piglia. Para mencionar um dos exemplos prévios mais notórios, cabe lembrar a intriga em torno da qual se desenvolve Respiración artificial (1980): um segredo de família um tio materno que fugira há muitos anos com uma mulher de duvidosa reputação, indo parar na prisão por algum tempo - é o núcleo do relato publicado pelo jovem escritor Emilio Renzi, personagem cuja primeira aparição no discurso ficcional dá-se no conto "La invasión”, incluído no livro homônimo, o primeiro publicado por Piglia, em 1967, ano e evento que encerram a última secção de diários do primeiro volume dos Diarios, como já foi assinalado. Em finais dos anos 1960 e nos anos de 1970, alguns artigos críticos de Piglia serão assinados, também, com o pseudônimo Emilio Renzi. ${ }^{3}$

É graças à publicação desse relato, que Renzi estabelece em Respiración artificial uma troca epistolar com Marcelo Maggi, o tio sumido do mapa familiar - e muito possivelmente do outro, já que a ficção transcorre no presente, e o livro, não custa recordar, é publicado em plena ditadura. Mas o encontro marcado entre tio e sobrinho não se dá, porque o primeiro não comparece, sem que se saiba o porquê. Esse tio, por sua vez, investiga a "verdadeira história" de Enrique Osorio, secretário do caudilho

\footnotetext{
3 Não é possível deter-se aqui nas implicações do gesto pelo qual Piglia atribui a autoria dos Diarios a Emilio Renzi, dessa derradeira transferência do eu a um ele que ao longo de sua obra foi se delineando como um misto de alter-ego, autofiguração do escritor e personagem. Graciela Speranza (2015), Martín Kohan (2017), Adriana Rodriguez Pérsico (2019), Susana González (2019), Edgardo Berg (2019), Julio Premat (2019), Teresa Orechia-Havas (2019), entre outros, abordaram a questão. Destaco apenas dois traços parcialmente complementares que vêm sendo assinalados com insistência por vários desses críticos: o distanciamento irónico, a despersonalização e/ou outridade. Sem renunciar ao pressuposto da existência de vínculos entre literatura e vida, a literatura de Piglia busca afastar-se das formas mais usuais de escrita do eu que pautaram a virada subjetiva dos anos 1990-2000 e resgatar uma noção de experiência entendida em termos benjaminianos.
} 
Juan Manuel de Rosas e parente de Luciano Osorio, seu ex-sogro, em cujas mãos se encontra um conjunto de papéis desse enigmático personagem da história argentina. Evidentemente Respiración artificial é muito mais do que esse drástico resumo: é uma releitura insidiosa da tradição literária nacional proposta por Renzi (segundo a qual Borges encerra a literatura argentina do século XIX), é a narração do hipotético encontro entre Kafka e Hitler em Praga e o postulado da literatura kafkiana como figuração daquilo que o escritor tcheco antevê nesse encontro fortuito com um pintor fracassado e medíocre, é... Mas é também essa intriga familiar formatada, no romance, sob o signo das linhagens oblíquas e enviesadas, escolhidas em substituição à herança linear imposta pela/pressuposta na cadeia pai/filho. É ali, em Respiración artificial, que Renzi afirma o seguinte: "Alguien, un crítico ruso, el crítico ruso Iuri Tinianov, afirma que la literatura evoluciona de tío a sobrino (y no de padres a hijos) expresión enigmática que nos ha de servir por el momento, ya que es el mejor resumen de tu carta que conozco" (PIGLIA, 1992, p. 19). ${ }^{4}$ A carta à qual Renzi está se referindo é a primeira que recebe de Marcelo Maggi, seu tio, que decide que "lo mejor va a ser pasarle el Archivo (con los documentos y las notas y los capítulos [do livro sobre Osorio] que ya he redactado a alguien de mi entera confianza" (pp. 71-72), ${ }^{5}$ e lega o arquivo a seu sobrinho Renzi. Mas a expressão também "serve" ou "convém" à leitura a ser proposta aqui.

No âmbito da produção crítica, cabe mencionar o ensaio publicado por Ricardo Piglia quase contemporaneamente a Respiración artificial, no ano de 1979, no segundo número de Punto de Vista: "Ideología y ficción e Borges" (1979). Nesse ensaio, Piglia lê na escrita borgeana um relato fragmentado e disperso que acompanha e sustenta a ficção de Borges, um núcleo que ordena seus textos para além da pluralidade de registros, gêneros e temas. Trata-se de uma ficção que não precede à obra, mas é seu resultado. Entretanto, ela figura as condições que tornaram possível a escrita e que justificariam a obra borgeana. À diferença de Arlt (essa espécie de tio maldizente, herético, sem credenciais legitimadas nem ancestrais reconhecidos, ostensivamente escolhido pelo jovem Piglia como modelo,

\footnotetext{
4 "Alguém, um crítico russo, o crítico russo Iuri Tinianov, afirma que a literatura evolui de tio para sobrinho (e não de pais para filhos). Expressão enigmática que por enquanto nos convém, já que é o melhor resumo que conheço para sua carta." (PIGLIA, 20oob, p. 17). 5 “[...] o melhor será passar o Arquivo (com os documentos e notas e capítulos que já redigi para alguém de minha inteira confiança” (PIGLIA, 20oob, p. 69).
} 
mas ao qual este atribuirá, também lembremos disso, a frase borgeana contida na epígrafe de Nombre falso, de 1975); à diferença de Arlt, a ficção de origem borgeana tem a forma de uma narração genealógica na qual o culto dos ancestrais desempenha um papel decisivo. As letras, a tradição intelectual, a literatura europeia (especialmente a inglesa), a biblioteca, a escrita, remetem à linhagem paterna; as armas, o ethos guerreiro e a exaltação da coragem, a prosápia nativa, a tradição oral, a voz, remetem à figura materna.

Essa ficção social e individual, que expressa tanto uma condição de classe como uma posição de sujeito, está representada em Borges por meio da relação com seus pais: "sustentada na diferença dos sexos, a família se divide em duas linhagens" e "essa dupla linhagem cruza e divide sua obra" (PIGLIA, 1981, p. 88). ${ }^{6}$ Evidentemente, "essa construção nada tem a ver com a (suposta) verdade de uma autobiografia", frisa Piglia no artigo; "é a elaboração retrospectiva de certos dados biográficos que são forçados a encarnar um sistema de diferenças e oposições” (p. 89).7 A expressão, como afirma Renzi em Respiración artificial, por enquanto "convém”, já que pode ser assumida como marco interpretativo provisório para ler alguns deslocamentos e tensões figurados na ficção de origem de Piglia.

Se, para Borges (segundo Piglia), ser escritor é realizar o desejo do paterno, para o jovem Renzi de Años de formación (ou, mais adequadamente, de um processo formativo que só se encerraria com a publicação de Respiración artificial, de acordo com a leitura proposta por Daniel Mesa Gancedo (2019) à qual será preciso voltar), para Renzi, inicialmente, é afrontá-lo. Isso, não obstante a ficção de origem da escrita estar indissoluvelmente vinculada ao pai, porque, como os leitores de Piglia sabem, é a militância peronista do pai e seu encarceramento após a derrocada de Perón, em 1955, o evento que deflagra a fuga clandestina da família de Adrogué para Mar del Plata, à revelia do filho (etambém da mãe), e, junto com o desterro forçado, o início da escrita dos míticos cadernos que Piglia manteve ao longo de décadas e proclamou mil vezes serem sua "verdadeira" obra, a "obra futura". Mas, simultaneamente, a origem, porque embora "no hay nada más ridículo que la pretensión de registrar la propia

\footnotetext{
6 "Apoyada en la diferencia de los sexos, la familia se divide en dos linajes", "ese doble linaje cruza y divide su obra.".

7 “[...] esa construcción nada tiene que ver con la verdad de una autobiografía, es más bien la reelaboración retrospectiva de ciertos datos biográficos que son forzados a encarnar un sistema de diferencias y oposiciones" (PIGLIA, 1981, p. 89).
} 
vida”, embora essa pretensão transforme automaticamente quem escreve um diário num “clouwn”, apesar disso, "estoy (está) convencido de que se no hubiese empezado a escribirlo aquella tarde [de 1957] jamás habría escrito otra coisa" (PIGLIA, 2007, p. 12), afirma o narrador da primeira parte de Prisión perpetua, livro de $1988 .^{8}$ O enunciado migra para a "Nota do autor" do primeiro volume dos Diarios de Emilio Renzi, publicado em 2015, e não duvido que um frequentador da obra de Piglia (um detetive buscador de fragmentos, por assim dizer) possa encontrá-lo em outros textos. Sabe-se: Piglia corta, transporta, modifica, edita e recontextualiza textos inteiros ou segmentos de textos em uma operação de leitura/(re)escrita incessante da própria obra, o que faz da montagem, do deslocamento e da recomposição de enunciados os dispositivos privilegiados de uma poética da experimentação, do processo, da movência, que transtorna cronologias e recusa clausuras, que faz da obra (provisória até o fim) um laboratório - e do escritor um (seu primeiro) leitor. ${ }^{9}$ Mas também teima em propor uma e outra vez essa ficção de origem. Hoje sabemos que houve alguns cadernos anteriores, os primeiríssimos cadernos de um adolescente, redigidos entre 1954 e $1956 .^{10}$ Piglia os escamoteou até o fim e elaborou insistentemente a versão que fez do pai o causante da escrita (não é difícil

8 "Não há nada mais ridículo do que a pretensão de registrar a própria vida"; "apesar disso estou convencido de que se não tivesse começado a escrevê-lo naquela tarde [de 1957] jamais teria escrito outra coisa" (PIGLIA, 1989, p. 13).

9 Sobre o caráter experimental da poética de Piglia, cf. especialmente o artigo de Orecchia Havas, já referido, e outro artigo anterior, de 2010, republicado em 2017. Segundo Julio Premat (2009), o processo de autofiguração do escritor como leitor e o intenso trabalho de prescrição de modos de ler a própria obra desenvolvidos por Piglia alcançariam uma expressão extremamente elaborada em El último lector, de 2005. A ideia, formulada com anterioridade à publicação dos Diarios, pode se fazer extensiva a essa derradeira escrita que, "embora se situasse no presente, já era ou já se sabia póstuma" (PREMAT, 2019, p. 1), como afirma o crítico em outro texto mais recente, dedicado aos Diarios de Emilio Renzi. 10 Embora não tenha consultado os cadernos depositados na Fireston Library da Princeton University, me baseio em duas fontes. Uma, oral: em palestra proferida na USP por Daniel Balderston em março de 2019, o crítico mencionou esses cadernos adolescentes, ao que tudo indica, anódinos. A outra menção, escrita, consta no artigo já citado de Orecchia Havas (2019, p. 20), que redimensiona a extensão e amplitude dos supostos trezentos e vinte e sete cadernos manuscritos e os reduz a algo em torno de oitenta e cinco exemplares, incluídos os cadernos das viagens a Cuba e China: "A série completa, contando os primeiríssimos exemplares da época da adolescência, que não foram transcritos, abarca de 1954 a maio de 1988, embora Piglia use às vezes algumas páginas finais de um caderno para registrar notas de anos muito posteriores" [La serie completa, contando los primerísimos ejemplares de la época de adolescencia que no han sido transcriptos, abarca desde 1954 hasta mayo de 1988, aunque Piglia usa a veces ciertas páginas finales de un cuaderno para consignar notas de años muy posteriores].

Remate de Males, Campinas-SP, v.39, n.2, pp. 586-6o9, jul./dez. 2019 - 591 
associar a ficção paranoica e a teoria do complô, entre outros traços, ao fantasma paterno), mas ao mesmo tempo o obstáculo inicial.

\section{II}

No primeiro volume dos Diarios de Emilio Renzi - mais precisamente, no texto inserido em seu interior, que leva o título de "Diario de un cuento" -, o leitor se depara com um dos vários episódios em que o pai é figurado como antagonista do aspirante a escritor. O avô, em contrapartida, é o possibilitador. E tambéméum dos muitos modelos do narrador enigmático que prolifera, tanto nas anotações de leitura como na "escuta" do jovem Renzi, de um modo de narrar que funda sua eficácia na elipse, no não dito, na interrupção, na teoria do iceberg: "A veces prendo el grabador y registro lo que cuenta [o avô Emilio]. Siempre es así, narra pequeños fragmentos, muy vívidos, pero se cortan, no concluyen" (PIGLIA, 2015a, p. 101). ${ }^{11}$

O texto retoma o relato do alistamento no exército italiano durante a primeira guerra por parte do avô Emilio, pai do pai de Renzi, fato evocado inicialmente "En el umbral" do livro (voltarei em breve a isto). Estamos em 1961, Renzi saiu de Mar del Plata e da casa dos progenitores, frequenta a universidade, faz a graduação de História. O "Diario de un cuento" (que pode ser considerado um sucedâneo da secção dos diários desse ano, devido à posição que ocupa no livro, mas é fundamentalmente um ensaio de transmutação do vivido em experiência literária), alterna duas narrações sob a rubrica de dias descontínuos. Uma delas, a da curta mas intensa relação de Renzi com Lucía, uma mulher mais velha, casada, colega de faculdade - e um pouco "louca", uma classe de sujeitos à qual será preciso retornar -. Trata-se da mulher que, ao abandonar Renzi e se despedir, recebe uma dracma das mãos de um mendigo e a entrega a Renzi. ${ }^{12}$ Não seria impossível ler essa narração como uma metamorfose $a$ mais, e simultaneamente como primeira ficcionalização das relações entre Renzi e Vicki, abordada nos diários do ano anterior, bem como da história entre Luciana e Emilio, do conto "Suave es la noche", do livro La invasión.

A outra linha narrativa se refere às visitas feitas por Emilio Renzi ao avô Emilio, que permanecera em Adrogué. O avô está velho e começou a

11 "Às vezes pego o gravador e registro o que ele conta, ou então o deixo falar [...] É sempre assim, ele narra pequenos fragmentos, muito vívidos, mas que se cortam, não concluem." (PIGLIA, 2017, p. 106).

$12 \mathrm{O}$ mendigo é/pode ser Steve, o protagonista de outro texto autônomo - "El nadador" inserido nos Diarios, e também, antes, em Prisión perpetua, é/pode ter sido Steve Restiff. 
perder a memória. Antes disso, durante o conflito bélico, ele "perde[era] a cabeça" e parara de cumprir o trabalho que lhe fora atribuído na secção de cartas de soldados mortos ou desaparecidos em combate: reunir os pertences dos defuntos e enviá-los aos familiares junto com uma missiva de condolências. Repentinamente, o avô deixa de enviar esses restos de guerra, começa a guardá-los e os leva consigo ao retornar à Argentina. É para pôr ordem nesses papéis (outra vez o arquivo, outra vez o legado) que o avô Emilio contrata o jovem Renzi e vira uma espécie de padrinho (ou de "pai indireto") do neto:

\author{
Martes \\ Desde que empezó a perder la memoria (dice) [o avô Emilio] está preocupado \\ y quiere ordenar sus papeles. Los médicos le han prohibido salir y eso es lo que \\ más nervioso lo tiene. \\ - No me perdi en Isonzo, mirá si me voy a perder (“extraviar”, dice) acá. -Se \\ queda pensando- Ya te di la plata, no? \\ Me dio la plata. Teme perder sus mapas, las fotos, las cartas; me contrató para \\ que le ordenara su archivo, me paga un sueldo [...] En realidad me paga la \\ carrera. "No quiero que seas un sobaco ilustrado", me dijo el hijo de puta de \\ mi padre. \\ - Esperaba que yo fuera abogado... \\ - Para que lo saques de la cárcel -se ríe el Nono (PIGLIA, 2015a, p. 100). ${ }^{13}$
}

\title{
Um segundo arremate não demora a chegar:
}

El abuelo está sentado otra vez al sol y canta en voz baja siempre la misma canción como un mantra (Bella ciao, bella ciao, ciao...).

[...] - Tu padre cómo va? Tampoco yo me hablo con él, no me gustan los médicos y tampoco me gustan los hijos directos, sabés, prefiero los hijos indirectos (PIGLIA, 2015a, p. 111).14

A opção pelos laços colaterais ou pela ascendência "salteada", para usar uma expressão de Macedonio, um dos pais indiretos escolhido por

13 “Terça-feira:/ Desde que começou a perder a memória (diz) está preocupado e quer organizar seus papéis. Os médicos o proibiram de sair, e é isso que o deixa mais nervoso./ Se não me perdi no vale de Isonzo, imagine se ia me perder (ele diz "extraviar") aqui. - Fica pensativo. - Já te dei o dinheiro, não é?/ Ele me deu o dinheiro. Tem medo de perder seus mapas, as fotos, as cartas; me contratou para organizar seu arquivo, com um salário [...] Na verdade, ele me paga os estudos. "Não quero que você seja um sovaco ilustrado", disse o filho da puta do meu pai./ - Queria que eu fosse advogado.../ - Para que você o tire da cadeia - ri o Nono" (PIGLIA, 2017, p. 105).

14 "Meu avô está de novo sentado ao sol cantando em voz baixa sempre a mesma canção, como um mantra (Bella ciao, bella ciao, ciao...) [...] - Teu pai, como está? Eu deixei de falar com ele, não gosto de médicos nem gosto dos filhos diretos, sabe?, prefiro os filhos indiretos." (PIGLIA, 2017, p. 117).

Remate de Males, Campinas-SP, v.39, n.2, pp. 586-6o9, jul./dez. 2019 - 593 
Renzi/Piglia, será a feição adotada pela poética que vai se delineando com o passar dos anos e dos livros, especialmente em Nombre falso (1975), Respiración artificial (1980), Prisión perpetua (1988) e La ciudad ausente (1992). ${ }^{15}$ Mas, nesse retrato de Renzi quando jovem, o imperativo parece ser a revogação do pai, simultaneamente causante e antagonista da escrita.

Ciente do salto argumentativo e da contradictio in adjecto que supõe pôr momentaneamente lado a lado o pai biológico (da ficção), que repudia o "sovaco ilustrado", e o pai simbólico, tido como o compêndio da cultura na década de 1960 - Borges -, arrisco dizer que ele também, nos anos de formação, é simultaneamente causante e rival, que a relação é agônica até encontrar um modo produtivo de lê-lo (de ponta cabeça); até achar a maneira de cruzá-lo com outras séries, como afirmava Tinianov, com tios excêntricos, "extravagantes", "intraduzíveis" (a adjetivação é de Renzi). Até conseguir subtrair-se à reprodução filial. O Piglia que escreve Los Diarios de Emilio Renzi encontrou há muitos anos as estratégias conduzentes a esse fim, é claro. Mas é como se tivesse querido deixar alguns vestígios dos anos de formação e do "ímpeto arrogante" desse jovem "idiota" (porque "eu era mais idiota do que sou agora”, diz Renzi, na soleira), que guarda pontos de contato com a figura do filho bastardo, proposta por Marthe Robert em Romance das origens; origens do romance. Um livro de 1973, sobre cuja leitura Renzi anota, na entrada da Sexta-feira de 5 de julho de 1974, do segundo volume, o seguinte:

\section{Viernes 5}

Leo el libro de Marthe Robert sobre la novela familiar freudiana como nudo básico en la historia de los orígenes de la narración moderna. Estudia a Robinson

$15 \mathrm{O}$ processo tem sido assinalado por alguns críticos, dentre os quais destaco Teresa Orecchia Havas devido à continuidade e minuciosidade com a qual vem trabalhando sobre a produção de Ricardo Piglia há quase duas décadas. Num artigo de 2006, republicado em 2012, e em outro já referido aqui, de 2010, republicado em 2017, examinam-se as transformações operadas nesse conjunto de títulos. O postulados de Orechia serão retomados no próximo item deste ensaio. Por ora interessa frisar que, segundo ela, nos textos que sucedem La invasión, "o peso da genealogia desloca-se do par simbólico pai/filho para tio/sobrinho", instituindo "um tipo de relação oblíqua que evita o âmbito do (mesmo) nome e propõe um lugar deslocado na genealogia” (ORECHIA, 2012, p. 281). Acrescento um dado biográfico do autor, não destacado por Orecchia Havas, que considero de interesse para o futuro andamento deste ensaio; trata-se do nome dos progenitores de Ricardo Emilio Piglia (seu nome civil): Pedro Piglia, o pai; Aída Renzi, a mãe. O deslocamento tem início portanto na própria escolha desse nome para o misto de autofiguração, alter ego e personagem, e se faz extensivo, nos Diarios, à figura desse avô paterno (materno).

Remate de Males, Campinas-SP, v.39, n.2, pp. 586-6o9, jul./dez. 2019 - 594 
Crusoe como el que niega al padre y se inventa un linaje y un territorio propio (PIGLIA, 2016, p. 359). ${ }^{16}$

Em várias entradas, tantoa crítica aos pares (esses escritores coetâneos que fazem parte de uma comunidade fraterna/fratricida na qual abundam os sentimentos infamiliares, no sentido freudiano), como a reivindicação "arrogante" e "idiota" de uma suposta originalidade, orbita em torno de ter ou não uma relação filial direta (reprodutiva) com esse outro genitor. Cito dois exemplos:

\begin{abstract}
Lunes [1965]
Cada tanto, una súbita confianza en el libro [La invasión], por ejemplo recién, caminando bajo la lluvia, después de tomar un vaso de leche y hablar con Briante. Dimos vueltas y vueltas sobre el estado de la literatura, él y yo estamos libres de la fiebre por Cortázar que ha invadido la mayor parte de las escrituras actuales; claro que Miguel está contaminado por Borges (por cierta idea de estilo "criollo") y por cierta adjetivación afectada que no lo deja encontrar la voz propia. Por mi parte, avanzo a ciegas, por la espesura, sin ninguna guía” (PIGLIA, 2015a, p. 208). ${ }^{17}$
\end{abstract}

\title{
Lunes
}

Formalmente y en su estilo, La invasión no tiene nada que ver con Borges - o tiene que ver como rechazo de su manera de entender la literatura. En eso me diferencio de todos los escritores, que en general le copian hasta el modo de escupir (PIGLIA, 2015a, p. 198). ${ }^{18}$

16 "Leio o livro de Marthe Robert sobre o romance familiar freudiano como nó básico da história das origens da narração moderna. Estuda Robinson Crusoé como o filho que nega o pai e inventa uma linhagem e um território próprio." (PIGLIA, 2019, p. 361).

17 "Segunda-feira:/ De quando em quando, uma súbita confiança no livro [A invasão]: agora há pouco, por exemplo, caminhando sob a chuva, depois de tomar um copo de leite e de conversar com o Briante. Ficamos falando e falando sobre o estado da literatura, eu e ele estamos livres da febre por Cortázar que invadiu a maior parte das escritas atuais; claro que o Miguel está contaminado por Borges... por certa adjetivação afetada que o impede de encontrar uma voz própria. Eu, de minha parte, avanço às cegas, em meio à espessura, sem guia." (PIGLIA, 2016, p. 219).

18 "Segunda-feira:/ Formalmente no seu estilo, $A$ invasão não tem nada a ver com Borges ou tem a ver como recusa de sua maneira de entender a literatura. Nisso eu me diferencio de todos os escritores, que em geral o imitam até no jeito de cuspir." (PIGLIA, 2016, p. 209). Para Daniel Mesa Gancedo (2019, p. 2), o primeiro marco da construção desse espaço beligerante, que define o campo no qual o escritor Renzi dá seus primeiros passos, tem uma remissão intertextual na soleira dos Diarios, onde o narrador diz estar lendo The Opposing Self, de Lionel Trilling, uma compilação de ensaios que "acompanham o desenvolvimento do 'eu antagônico' característico da modernidade”. A paranoia, enquanto sintoma paterno, desloca-se da cena "estritamente político-partidária para a arena intelectual" - que não deixa de ser política - nos anos de formação, anos que abarcariam não apenas o primeiro volume homônimo dos Diarios, mas uma parte importante do segundo: grosso modo, 


\section{III}

Num ensaio de 2010, republicado no ano de 2017, Teresa Orecchia postula uma mudança de rumo nos escritos de Piglia a partir dos anos de 1970, anos que deixariam atrás a feição realista dos relatos curtos de La invasión e introduziriam um conjunto de preocupações metaliterárias. Nesses textos de passagem, por assim dizer, comparece de modo recorrente a questão das origens da criação e das relações do escritor com o processo da escrita. De acordo com a crítica, depois de um momento fundacional no qual tanto a escrita como a figura do autor se vinculam seja à relação com a função paterna (Nombre falso, 1975, especialmente "El fin del viaje"), seja à posição de um sujeito cercado pela morte (Respiración artificial, 1980), os textos de Piglia acabariam por construir uma nova articulação do mito da criação literária, organizada em torno da emergência de uma voz feminina, ambivalente e sedutora, que seria a voz própria da literatura e cuja alegoria estaria dada pela máquina de narrar de La ciudad ausente, romance de 1992. Gostaria de aproveitar os lineamentos fundamentais dessa hipótese, que faz de Prisión perpetua (1988) tanto um texto de inflexão como uma espécie de "mirante" a partir do qual o autor relê e reorganiza a obra precedente, para estendê-la à aproximação aqui proposta acerca da nova (derradeira) releitura/reescrita dos anos de formação presente em Los diarios.

É precisamente em meados dos anos de 1970 e em Nombre falso (que será incluído posteriormente em Prisión perpetua), onde se podem ler as seguintes palavras de Kostia, endereçadas ao narrador, crítico e investigador envolvido na busca do suposto inédito de Roberto Arlt (alguém que já perto do final do livro será identificado como Ricardo Piglia):

Lea Escritor fracasado: eso es lo mejor que Roberto Arlt escribió en toda su vida. La historia de un tipo que no puede escribir nada original, que roba sin darse cuenta. Así son todos los escritores en este país, así es la literatura de acá.

até a publicação de Respiración artificial e o retorno da Argentina à democracia. Partindo dessas premissas, Gancedo examina o estreito e paradoxal vínculo amizade/inimizade estabelecido com um conjunto de escritores que estão se formando, e cuja produção vem a público nesse período (Jorge ["Dipi"] di Paola, Miguel Briante, Juan José Saer, Manuel Puig, dentre outros), bem como com intelectuais e escritores um pouco mais velhos (León Rozitchner ou David Viñas). As tensões entre amizade/afinidade estética/rivalidade também são objeto de reflexão do texto de Martín Kohan (2019), publicado neste Dossiê. 
Todo falso, falsificaciones de falsificaciones. Arlt se dio cuenta que tenía que escribir sobre eso, metido hasta la garganta. Mire - dijo -, haga una prueba, compare Escritor fracasado con ese cuento de Borges, con Pierre Menard: son la misma cosa. El tipo que no puede escribir si no copia, si no falsifica, si no roba: ahí tiene un retrato del escritor argentino. A usted le parece que está mal? Y sin embargo no está mal, está muy bien: se escribe desde donde se puede leer (PIGLIA, 1975, pp. 132-133). ${ }^{19}$

Uma das várias declarações em que Piglia reivindicaria posteriormente essa espécie de genealogia cruzada e inventada para si, enquanto "tradição na qual desejaria ser incluído”, pode ser lida na entrevista concedida a Graciela Speranza para Página 12 (12/11/1992), que leva o título de Primera persona, recolhida na versão ampliada de Crítica y ficción (2000). Ao ser convidado a falar sobre o diálogo e a ficcionalização recorrente da tradição argentina em seus textos, mas também das estratégias para ultrapassá-la, o autor diz:

Creio que a primeira vez que eu pensei nisso foi há muitos anos, quando comecei a entender o que tinham em comum Borges e Arlt, porque em um dado momento me dei conta de que no fundo os dois estão narrando realidades ausentes, trabalhando a contrarrealidade. Seja a realidade dos conspiradores, dos inventores, ou dos hermeneutas, dos teólogos ou os detetives, os dois estão construindo realidades ausentes, vidas alternativas (PIGLIA, 2000a, p. 145)..$^{20}$

19 "Leia Escritor fracassado: é a melhor coisa que Roberto Arlt escreveu em toda a sua vida. A história de um cara que não consegue escrever nada de original, que rouba sem perceber. Todos os escritores deste país são assim, a literatura daqui é assim. Tudo falso, falsificações de falsificações. Arlt percebeu que tinha que escrever sobre isso, enfiado até o pescoço. Olhe - disse -, faça um teste, compare Escritor fracassado com aquele conto do Borges, com Pierre Menard: são a mesma coisa, O cara que não consegue escrever se não copiar, se não falsificar, se não roubar: é um retrato do escritor argentino. O senhor acha que não é direito? Mas está certo, é isso mesmo: escreve-se a partir de onde se pode ler." (PIGLIA, 1988, p. 47). A frase que propõe a equiparação Arlt/Borges ("Mire - dijo-, haga una prueba, compare Escritor fracasado con ese cuento de Borges, con Pierre Menard: son la misma cosa”) consta na primeira edição de Nombre falso, de 1975, mas foi suprimida nas edições posteriores consultadas (Seix Barral, 1997, e Anagrama, 2002). Agradeço a Imelda Ferrero a generosidade de me facilitar o acesso a essa primeira edição. Na tradução para o português, a frase permanece porque foi tomada como base a edição de 1975, embora o livro contenha unicamente a nouvelle "Nome falso. Homenagem a Roberto Arlt", e não os outros contos (variáveis, conforme a edição) que integram o volume em espanhol.

20 "Creo que la primera vez que yo pensé en eso fue hace muchísimos años, cuando empecé a entender qué tenían en común Borges y Arlt, porque en un momento dado me di cuenta que en el fondo los dos están narrando realidades ausentes, trabajando la contrarealidad. Ya sea la realidad de los conspiradores, de los inventores, o de los hermeneutas, los teólogos o los detectives, los dos están construyendo realidades ausentes, vidas alternativas."

Remate de Males, Campinas-SP, v.39, n.2, pp. 586-6o9, jul./dez. 2019 - 597 
Evidentemente, El escritor fracassado de Arlt e Pierre Menard de Borges podem ser vistos como "a mesma coisa", apreendidos no que eles "têm em comum", a posteriori, depois que a leitura/escrita de Piglia equipara (sem anular a disparidade) tradições e linhagens mantidas a distância pelos escritores de Contorno, grupo pioneiro no resgate de Arlt e no questionamento da concepção de literatura representada pela revista Sur, à qual o nome de Borges aparece associado. ${ }^{21} \mathrm{~A}$ ficção de origem de Renzi/Piglia parte desse antagonismo - de La invasión como "rejeição do modo borgeano de entender a literatura" e da adoção de um universo de tonalidade fortemente arltiano -, para conduzi-lo à peculiar equivalência proposta por Kostia. ${ }^{22}$

Nesse processo, as proposições do artigo "Roberto Arlt: una crítica de la economía literaria”, publicado em Los libros, em 1973 (PIGLIA, 2015c), resultam fundamentais, dado que ali aparecem múltiplas considerações sobre "as determinações econômicas que regem toda leitura, sobre os códigos de classe que decidem a circulação e a apropriação literárias", postos em evidência pela literatura de Arlt (PIGLIA, 2015c, p. 50), ${ }^{23}$ e que se contrapõem ao código de Sur, representado, nesse texto, pela figura de José Bianco (mas trata-se de um retrato que mantém pontos de contato com o Borges de "Ideología y ficción", no tocante à relação "fluida" e "familiar" com a cultura entendida como herança). Cito uma extensa passagem desse texto:

21 Entre os principais expoentes de Contorno cabe mencionar a Ismael e David Viñas, Juan José Sebreli, Oscar Massotta e Adolfo Prieto.

22 Cito novamente um dos fragmentos já citados e acrescento a última frase: "Formalmente y en su estilo, La invasión no tiene nada que ver con Borges -o tiene que ver como rechazo de una manera de entender la literatura-. En esto me diferencio de todos los escritores, que en general le copian hasta el modo de escupir. Nada tampoco con Cortázar, la otra plaga. Temáticamente la influencia es Arlt -demasiadas delaciones" (PIGLIA, 2015a, p. 198) [Formalmente no seu estilo, $A$ invasão não tem nada a ver com Borges - ou tem a ver como recusa de sua maneira de entender a literatura. Nisso eu me diferencio de todos os escritores, que em geral o imitam até no jeito de cuspir. Nada a ver com Cortázar, a outra praga. Tematicamente a influência é Arlt - demasiadas delações] (PIGLIA, 2016, p. 209). A que temporalidade adscrever o irônico comentário final? De fato, basta pensar num conto como "Mi amigo" para notar que a influência, o roubo e a falsificação já aparecem fundidos nessa narrativa (e em várias outras) de La invasión. Não surpreende que nessa fase iniciática Renzi "pendure uma foto de Roberto Arlt no quarto" onde se instala, para terminar o livro de contos (Diario de 1966, entrada do 26 de fevereiro). 23 "[...] as determinaciones económicas que rigen toda lectura, los códigos de clase que deciden la circulación y la apropiación literarias”. 
Basta reler o artigo que José Bianco lhe dedicou [a Arlt] em 1961 para ver de que modo Arlt transgride o espaço de leitura. Neste caso, o código de Sur: leitura de classe que refere - justamente ao contrário de Arlt - o acesso fluido a uma cultura "familiar". Na verdade, o que se lê por baixo do texto de Bianco é a definição dessa propriedade que é necessário exibir para escrever: "Arlt não era um escritor mas um jornalista, na acepção mais restrita do termo. Falava o lunfardo com sotaque estrangeiro, ignorava a ortografia, nem se fale da sintaxe". A insistência sobre as faltas de Arlt não é outra coisa que a marca do descrédito [...] os erros são - outra vez - o lapsus onde se perdem os títulos de propriedade e se deixa ver uma condição social [...] Haveria uma carência "natural", irremediável: uma fatalidade. Arlt se encarrega de lembrar que essa carência é econômica, de classe: na sociedade, a cultura é uma economia; trata-se de ter uma cultura, quer dizer, de poder pagar. Bianco, por sua vez, funda sua leitura na desigualdade e, ao universalizar as posses de uma classe, torna seus "bens" as qualidades espirituais nas quais se sustenta um sistema de valor [...] O respeito é um reconhecimento: neste caso, há certos títulos dos quais Arlt carece. Ou melhor, há certos títulos que Arlt admite ter recebido em empréstimo: não são dele, e essa é a dívida que deve pagar [...] Ora: se aquilo que serve para desacreditá-lo fosse justamente o que ele não quis deixar de exibir? Quero dizer, se o mérito de Arlt tivesse sido mostrar o que não há, fazer ver a dívida que se contrai ao praticar - sem títulos - a literatura? Nesse sentido, suas carências vão além de si mesmo: assinalam os limites concretos de certa leitura, a fronteira - desvalorizada, empobrecida - de um espaço que é o da literatura argentina.

El juguete rabioso é o melhor exemplo das condições dessa leitura: história de uma apropriação, no jogo dos intercâmbios, dos desvios, das substituições que constituem o texto, narra o trajeto que é necessário percorrer para ganar-se uma escrita (PIGLIA, 2015c, p. 51). ${ }^{24}$

24 "Basta releer el artículo que José Bianco le dedicara [a Arlt] en 1961 para ver de qué modo Arlt transgrede un espacio de lectura. En este caso, el código de Sur: lectura de clase que refiere -justamente al revés de Arlt- el acceso fluido a una cultura 'familiar'. En realidad lo que se lee por debajo del texto de Bianco es la definición de esa propiedad que es necesario exhibir para poder escribir: 'Arlt no era un escritor sino un periodista, en la acepción más restringida del término. Hablaba el lunfardo con acento extranjero, ignoraba la ortografía, qué decir de la sintaxis'. La insistencia sobre las faltas de Arlt no son otra cosa que las marcas de un descrédito [...] los errores son -otra vez- el lapsus donde se pierden los títulos de propiedad y se deja ver una condición social [...] Habría una carencia "natural", irremediable: una fatalidad. Arlt se encarga de recordar que esta carencia es económica, de clase: en esta sociedad, la cultura es una economía, por de pronto se trata de tener una cultura, es decir, poder pagar. Por su lado, Bianco funda su lectura en la desigualdad y al universalizar las posesiones de una clase hace de sus "bienes" las cualidades espirituales en que se apoya un sistema de valor [...]. El respeto es un reconocimiento: en este caso hay ciertos títulos de los que Arlt carece. Más bien hay ciertos títulos que Arlt admite haber recibido en préstamo: no son de él y es esta deuda la que debe pagar. [...] Ahora bien ¿y si esto que sirve para desacreditarlo fuera justamente lo que él no quiso dejar de exhibir? Quiero decir ¿y si el mérito de Arlt hubiera sido mostrar lo que no hay, hacer ver la deuda que se contrae al practicar -sin títulos- la literatura? En este sentido, sus carencias van más allá de sí mismo: marcan los límites concretos de una cierta lectura, la frontera - 
Apropriar-se de Borges a partir de Arlt, torná-los intercambiáveis embora se mantenham (se façam ouvir) as dissonâncias, a diversidade de materiais e de discursos sociais mobilizados nos textos de um e de outro, é a operação em andamento da qual, talvez, uma anedota registrada nos Diarios possa considerar-se uma espécie de cena originária, de condensação dos elementos em jogo a serem equacionados na leitura/ escrita por vir.

É 1968, Renzi/Piglia já publicou La invasión, foi contemplado com o prêmio Casa de las Américas, viajou a Cuba, e a partir de então intensifica as anotações de leitura sobre procedimentos e formas narrativas, retoma e abandona alternativamente o projeto de um romance (que será, muitos anos depois, Plata quemada), frequenta bares e reúne-se com amigos, associados à serie $B$ (mas não só) no segundo volume, Los años felices:

\begin{abstract}
Martes.
Serie B. Anoche David. Fui a verlo por una reunión con León. Me recibe con una sonrisa enigmática. "A vos te gusta Borges, no?” Yo sigo caminando hacia el medio del departamento y veo un libro sobre el escritorio. "Qué trampa me estás preparando?", le digo. David se tira hacia atrás mientras agarra el libro y me golpea, ofendido, el brazo. "Pero no, viejo", dice. Después gran confusión mía, que trato de exagerar mi agradecimiento para disipar el malentendido. Me ha regalado la primera edición de El idioma de los argentinos, con la dedicatoria de Borges, a la que él le agregó otra, escrita con grandes trazos. Me doy cuenta de que robó el libro de José Bianco porque conozco el modo en que Pepe encuaderna los libros, pero no le digo nada (PIGLIA, 2016, p. 67).25
\end{abstract}

A inquirição sarcástica, o presente (que é um roubo) e a dedicatória sobrescrita procedem daquele que, em diversos momentos dos Diarios,

desvalorizada, empobrecida- de un espacio que es el de la literatura argentina. El juguete rabioso es el mejor ejemplo de las condiciones de esta lectura: historia de una apropiación, en el juego de los intercambios, los desvíos, las sustituciones que constituyen el texto se narra el trayecto que es necesario recorrer para ganarse una escritura." A expressão ganarse em espanhol comporta um engajamento do sujeito que se dilui no português "ganhar" e que estaria mais perto de chegar a ter ou a possuir.

25 “Terça./ Serie B. Ontem à noite, David. Fui à casa dele para uma reunião com o León. Ele me recebe com um sorriso enigmático. 'Você gosta de Borges, não é?' EU continuo caminhando para o interior do apartamento e vejo um livro sobre a mesa. "Que cilada você armou?", pergunto. O David recua e pega o livro, enquanto me dá um soquinho no braço, ofendido. “Que é isso, che?, diz. Depois eu, muito constrangido, tentando exagerar minha gratidão para dissipar o mal-entendido. Ele me presenteou com a primeira edição de El idioma de los argentinos, com uma dedicatória do próprio Borges, à qual o David acrescentou outra, escrita com traços largos. Logo percebo que o livro foi roubado do José Bianco, porque conheço o jeito como o Pepe encaderna seus livros, mas não digo nada" (PIGLIA, 2019, p. 70).

Remate de Males, Campinas-SP, v.39, n.2, pp. 586-6o9, jul./dez. 2019 - 600 
assume sucessiva e alternadamente o papel de contrafigura paterna, de amigo mais velho (quase um tio) ou de igual (quase um duplo), no qual Renzi enxerga ora qualidades e virtudes, ora antevê riscos e ameaças: David Viñas. $^{26}$

Os leitores do primeiro volume dos Diarios sabem que o avô Emilio irrompe por primeira vez no texto liminar intitulado "En el umbral", ${ }^{27} \mathrm{e}$ constitui uma novidade no universo Piglia atrelada à linhagem italiana de um escritor que, aí, na soleira, dirá ter se sentido, às vezes - "acima de tudo" - um escritor "ítalo-argentino" (algo que talvez convide a pensar no parcial descuido da crítica em relação a essa tradição - plural - que perpassou a cultura argentina moderna e que ressurge nessa singular evocação tardia). A figura desse "pai indireto" permitirá acrescentar à genealogia alterna

26 Abordar a intensa, complexa e variável relação Renzi (Piglia)/Viñas apresentada nos Diarios excede o propósito deste ensaio. Remeto o leitor interessado à secção que leva o título "La serie 'V': David Viñas", do excelente artigo de Mesa Gancedo (2019). Sem atentar para a cena aqui destacada, mas para outros episódios protagonizados por Renzi/Viñas ao longo dos Diarios, Gancedo propõe ler Viñas como uma espécie de dublê de corpo, no qual o jovem Renzi experimenta seus próprios temores e conflitos. Contrafigura paterna de início, em função da perspectiva adversa ao peronismo de Viñas. Modelo heroico de escritor, com o qual Renzi aprende, mas que também opera como advertência irônica (o sucesso faz "surgir o pior" de Viñas, que "funciona muito melhor quando pensa como um perdedor” - vol. II, Domingo 4/6/1972). Defensor de certa concepção de literatura que repercute diretamente na própria imagem de Renzi como escritor (ao contrário de Beatriz Guido, Viñas "é muito melhor que seus textos" - vol. I, Quarta-feira, 16/12 1964; seus relatos insistem na explicitação do sentido das ações narradas" - vol. I, Domingo 15/1/1967 -, ao invés de operar com a elipse e o não dito). Simultaneamente, o Viñas crítico parece antecipar as estratégias do discurso crítico de Renzi/Piglia ("Quando fala de literatura é muito sagaz, busca seu lugar e reconstrói continuamente a história da literatura argentina” - vol. II, quinta-feira 1/6/1972; "combina com excessiva segurança toda a história da literatura argentina” - vol. II, Domingo 2/8/1970). Confrontação e afinidade alternam-se, então, nesses Diarios do período formativo, os quais, segundo Gancedo, buscariam fazer justiça a um nome e preencher tardiamente uma lacuna na genealogia de Renzi.

27 En el umbral foi publicado previamente em 2015 sob o título de "Los libros de mi vida. Páginas de una autobiografía futura”, no número 15 da revista La Biblioteca, dedicado a Ricardo Piglia (El arte de narrar: variaciones sobre Ricardo Piglia, 2015). Como destaca Orecchia Havas (2019), exceção feita de um parágrafo que se refere ao pai do narrador (no qual precisamente se reitera o episódio da fuga da família a Mar del Plata e do início da escrita de um diário) e de duas notas de rodapé, os escritos coincidem. O número de $L a$ Biblioteca também reproduz textos de difícil acesso publicados pelo jovem Piglia, como o artigo sobre Pavese (El escarabajo de oro, n. 17, 1963), além dos publicados na revista Los Libros entre 1969 e 1975 e os artigos que apareceram em Punto de Vista.

Remate de Males, Campinas-SP, v.39, n.2, pp. 586-609, jul./dez. 2019 - 601 
construída ao longo dos textos (Arlt, Hemingway, Fitzgerald, o policial norte-americano, Gombrowicz, Joyce, a sombra omnipresente de Borges, que irrompe em seguida) uma série de nomes e de títulos que vão de Cuore, de Edmundo de Amicis, ao Diário da guerra ${ }^{28}$ e La cognizione del dolore, de (outro Emilio) Gadda. A relação dos "livros da vida" de Renzi - não os escritos, mas os lidos, sequer os livros, mas o modo de lê-los será a forma escolhida para essa rememoração liminar, composta por um conjunto de cenas de leitura (MOLLOY, 1996), mediante as quais se traça uma das trilhas da "autobiografia seriada" ensaiada, inquirida e sabotada por Renzi ao longo dos Diarios. E essa série de cenas de leitura - a primeira, porque, mal tendo concluído a enumeração, propõe-se outra que muda o rumo em direção às leituras movidas pela paixão, pelo desejo de dizer algo a uma mulher -, essa primeira série começa e acaba na biblioteca do avô, está emoldurada por sua presença (também pela presença da sombra borgeana, é claro, com a qual abre e fecha essa tragicomédia tardia, protagonizada por um Renzi agora velho, tão velho quanto o avô, que manca a causa de um "pequeno probleminha de saúde" (PIGLIA, 2015a, p. 29): sabemos, Piglia estava morrendo por causa de uma doença terrível, mas recusa o pathos trágico e opta pelo distanciamento irônico até o fim). Trata-se de uma série flanqueada e pautada pelos homens, então, mas escandida pelas mulheres, que ensinam a ler fazendo ler em voz alta - a mãe, a professora Molinari -, ou para as quais mais tarde ele tentará dizer alguma coisa (seduzi-las) a partir do lido.

Antes de terminar este ensaio, será necessário referir-se a elas, as mulheres, e à voz enquanto matriz de uma enunciação narrativa fluvial, à deriva, delirante, que põe a circular segredos de família - ou talvez seria melhor dizer fofocas, se pensarmos na estrutura da fofoca enquanto modelo da ficção, tal como propõe Edgardo Cozarinsky (2013). Uma palavra por vezes festiva e lúdica no âmago da dor: lembremos de María, a musa mexicana que transcreve - e melhora - o que dita um Renzi que já não pode escrever, que está prostrado na cama, no final desse primeiro Diario, em "Canto rodado". Uma cena delirante, no sentido etimológico, que tira de seu curso trágico a agonia e a transforma em gargalhada, jogo verbal, utopia joyceana do escritor ítalo-argentino: "Donde yo digo poemas, ella escribe problemas, donde yo digo, refiriéndome a mis amigos

28 Giornale di guerra e di prigionia (1955).

Remate de Males, Campinas-SP, v.39, n.2, pp. 586-6o9, jul./dez. 2019 - 602 
alfonsinistas, cívicos, ella traduce muy propiamente cínicos" (PIGLIA, 2015a, seção "Canto rodado", p. 345). ${ }^{29}$

O tempo da conversa implícita endereçada a um interlocutor nunca identificado, que se desenvolve "En el umbral" (outra vez, a ficção de oralidade), remete ao presente da escrita dos Diarios e evoca, dessa posição, um tempo anterior, descontínuo, o das "leituras da minha vida". Cito o início:

- Desde chico repito lo que no entiendo - se reía retrospectivo y radiante Emilio Renzi esa tarde en el bar de Arenales y Riobamba -. Nos divierte lo que no conocemos; nos gusta lo que no sabemos para qué sirve.

A los tres años le intrigaba la figura de su abuelo Emilio, sentado en el sillón de cuero, ausente en un círculo de luz, los ojos fijos en un misterioso objeto rectangular. Inmóvil, parecía indiferente, callado. Emilio el chico no comprendía muy bien lo que estaba pasando [...] directamente, imitaba lo que veía hacer. Entonces, esa mañana se trepó a una silla y bajó de una de las estanterías de la biblioteca. Un libro azul. Después salió a la calle y se sentó en el umbral con el volumen abierto sobre las rodillas.

[...] Vivíamos [em Adrogué] en una zona tranquila, cerca de la estación de ferrocarril, y cada media hora pasaban ante nosotros los pasajeros que habían llegado en el tren de la capital. Y yo estaba ahí, en el umbral, haciéndome ver, cuando de pronto una larga sombra se inclinó y me dijo que tenía el libro al revés (PIGLIA, 2015a, p. 15)..$^{30}$

A sombra, pensa Renzi, “deve ter sido" a de Borges: "En ese entonces solía pasar los veranos en el Hotel Las Delicias, porque a quién sino al

29 "Onde eu digo poemas, ela escreve problemas; onde eu digo, referindo-me aos meus amigos alfonsinistas, cívicos, ela traduz muito apropriadamente cínicos." (PIGLIA, 2017, p. 364).

30 “- Desde pequeno repito o que não entendo - ria Emilio Renzi retrospectivo e radiante naquela tarde, no bar da Arenales com a Riobamba. Achamos divertido o que não conhecemos; gostamos do que não sabemos para que serve. Aos três anos ficava intrigado com a figura do seu avô Emilio sentado na poltrona de couro, ausente dentro de um círculo de luz, os olhos fixos num misterioso objeto retangular. Imóvel, parecia indiferente, calado. Emilio, o menino, não entendia muito bem o que estava acontecendo [...] simplesmente imitava aquilo que via os outros fazerem. Então, naquela manhã subiu numa cadeira e tirou um livro azul de uma das estantes da biblioteca. Depois foi até a porta da rua e se sentou na soleira com o volume aberto no regaço. [...] Morávamos [em Adrogué] num lugar tranquilo, perto da estação de trem, e a cada meia hora passavam pela nossa calçada os passageiros vindos da capital. E lá estava eu, na soleira, querendo ser visto, quando de repente uma sombra comprida se inclinou para me dizer que o livro estava de ponta cabeça." (PIGLIA, 2017, p. 15).

Remate de Males, Campinas-SP, v.39, n.2, pp. 586-6o9, jul./dez. 2019 - 603 
viejo Borges se le puede ocurrir hacerle esa advertencia a un chico de tres años?" (PIGLIA, 2015a, p. 15).31

Salto os termos intermediários da primeira série e cito o trecho que "conclui" a "história dos livros da vida de Renzi" e que (re)conduz aos anos de 1960-1961, quando o avô Emilio contrata o neto para pôr ordem nos papéis:

En el cuarto del fondo de la casa de mi abuelo estaba la biblioteca donde encontré el libro azul, pero ahora junto con el Diario de la guerra, de Carlo Emilio Gadda. Lo descubrí en aquel tiempo cuando estudiava en La Plata y venía a visitarlo, una edición de La cognizione del dolore. Gadda había vivido en la Argentina y su novela, situada en un pueblo de Córdoba, los vecinos, aterrorizados por la inseguridad, contrataban un equipo de vigilancia privada y ellos -los custodios- eran quienes iban asesinando a esos argentinos del barrio cerrado, uno atrás de otro. Un vidente! Gadda entendió todo al toque en una novela de 1953.

Cómo se podía escribir sobre la Argentina? Se veía claro en Los siete locos, en Trans-Atlántico y en La cognizione del dolore. [...] Arlt, Gombrowicz, Gadda. En cuanto a mí, yo, que era un hijo y nieto de italianos, me he sentido a veces sobre todo un escritor ítalo-argentino [...] Me hubiera gustado ser sobrino de Carlo Emilio Gadda, pero tengo que conformarme, decía Renzi, con ser sólo su descendiente voluntario pero ilegítimo y no reconocido... (PIGLIA, 2015a, p. 25$) \cdot 3^{32}$

Tios excêntricos, sobrinhos ilegítimos, pais indiretos: é esse o núcleo masculino eleito como ficção de origem inicialmente tramada contra (e com) o pai, à qual, perto do fim, acrescenta-se mais um nome, Gadda, num gesto que relança sua literatura para as tensões do presente: "Um vidente! Gadda entendeu tudo de uma tacada, num romance de 1953”.

\footnotetext{
31 "Naquela época ele costumava passar o verão no hotel Las Delicias, e só mesmo o velho Borges para fazer essa advertência a uma criança de três anos, não é?” (PIGLIA, 2017, p. 15). 32 "No quarto dos fundos da casa do meu avô ficava a biblioteca onde encontrei aquele volume azul, agora ao lado do Diário da guerra, de Carlo Emilio Gadda. Eu o descobri naquele tempo em que estudava em La Plata e ia visitá-lo, junto a uma edição de $L a$ cognizione del dolore. Gadda vivera na Argentina e, no seu romance, ambientado num vilarejo de Córdoba, os moradores, apavorados com a insegurança, contratavam uma equipe de vigilância privada, e eles - os seguranças - é que iam assassinando esses argentinos do condomínio fechado, um após o outro ... Um vidente! Gadda entendeu tudo de uma tacada, num romance de 1953./ Como escrever sobre a Argentina então? A resposta salta aos olhos em Os sete loucos, em Trans-Atlântico e La cognizione del dolore. [...] Arlt, Gombrowicz, Gadda. Quanto a mim, eu... me senti por vezes um escritor ítalo-argentino [...] Eu gostaria de ter sido sobrinho de Carlo Emilio Gadda, mas tenho que me contentar, dizia Renzi, em ser apenas descendente voluntário, mas ilegítimo, e não reconhecido..." (PIGLIA, 2017, pp. 25-26).
}

Remate de Males, Campinas-SP, v.39, n.2, pp. 586-6o9, jul./dez. 2019 - 604 
Talvez seja oportuno recordar aqui a consideração de Villoro (2015, p. 28), expressa em "A arte de ler": "ler de ponta cabeça, por acidente, é um erro; ler de ponta cabeça com método permite a decodificação. O galimatias do leigo é a mensagem do espião". O escritor mexicano se refere à cena da leitura situada no liminar de "Los livros de mi vida", e acrescenta: "Foi um momento difícil para o ego, mas foi revelador para a consciência. O futuro do escritor dependeria de retornar propositivamente a esse gesto" (p. 28). A frase convida a rever o que vem sendo enunciado neste ensaio, pensando na sombra do pai como modelo inicialmente confrontado e progressivamente processado (reescrito de ponta cabeça) graças à intermediação dessa família excêntrica, que traz para a ficção de Piglia outros materiais e outras vozes sociais - que degrada, no sentido etimológico (faz descer um degrau, ou vários), a poética borgeana.

Para terminar (sem concluir) proponho um breve comentário acerca dessa essa outra ficção de origem da escritura de Piglia, associada à voz das mulheres.

Como já foi assinalado, Orecchia Havas examinou em detalhe o que considera uma mudança de rumo nos relatos publicados por Piglia a partir dos anos de 1970, que iriam remodelando aos poucos o mito da criação, para reorganizá-lo em torno da emergência de uma voz feminina. Essa nova articulação do mito da criação artística teria seu ponto culminante em La ciudad ausente (1992) e em Elena, a mulher-máquina de narrar. Mas os antecedentes de personagens narradoras (ainda que não necessariamente de sua voz enquanto instância enunciativa) são múltiplos e possuem várias características em comum: trata-se de mulheres que costumam ser meio (ou muito) "loucas", que põem a circular uma palavra ora hermética (a louca de "El Relato de la loca y el crimen"), ora enigmática (a Lucía Nietzsche de "El fluir de la vida", incluído em Prisión perpetua), que conhecem e praticam a "arte da interrupção" (é o que se diz da Lucía com a qual se envolve Renzi aos 20 anos, à qual já me referi, e que faz parte do "Diario de un cuento"). Elas parecem ser uma variante oral da teoria do iceberg, variante que prenuncia as possibilidades contidas na incessante retomada, reformulação e recombinação de núcleos narrativos que, por obra do corte, da alternância e da retomada, permitem operar a passagem das formas breves para as de maior extensão (mantendo, no entanto, a abertura e o dizer enigmático das formas breves iniciais). A ficção de 
origem desse modo de narrar pode ser lida no último texto de Los diarios de Renzi. Años de formación e leva o título de "Canto rodado".

"Canto rodado" é uma nouvelle que começa evocandoa figura materna, “depositária” e "transmissora” das histórias da família, que contará para Emilio, o filho, a história secreta do avô Emilio, após voltarem do enterro deste. O tempo da cena rememorada é 1968... ou 1969 (Renzi hesita, não lembra direito do ano, talvez porque as coisas importantes ocorram nesse tempo incerto que continua ocorrendo). Mas é o Emilio Renzi velho quem evoca o episódio. E, como há muito que ele aprendeu a lição materna, a nouvelle é um enxame de relatos que proliferam, se interrompem, se revezam, recomeçam: uma montagem, outra vez. Por isso, além da história até então oculta do avô Emilio, menciona-se um primo que tira o pai da sepultura e passeia com o cadáver sob a lua, a de uma tia alcoólatra e belíssima que jamais sai da casa e ouve o tempo todo pelo rádio os tangos de Gardel, a história do tio Anselmo, um médico que de repente imagina ter sido acometido por uma doença de pele, se reclui, e cobre o rosto com um véu durante anos (na história ressoa "El tintorero enmascarado" de Borges, na qual ressoa "O profeta velado" de Hawthorn); ao mesmo tempo que se introduz o metadiscurso e se reflete sobre como narrar, sobre a situação da literatura atual e o "turismo cultural", que se espalham indícios do "probleminha de saúde" de Renzi - que relata alguns pormenores da escrita do Diario (que lemos) e do auxílio prestado pela musa mexicana, que o ajuda a transcrever os cadernos. É para ela que Renzi dita (agora é a vez da voz) os trechos citados: "quando eu digo poema, ela...".

Examinar os pormenores da "história oculta” narrada por Ida Maggi, a mãe, história que "possibilita entrever" outra razão para o alistamento do avô Emilio, exigiria a escrita de outro ensaio como este. Baste indicar que esse relato envolve outra mulher, Matilde Araoz, amante do avô; as indecisões dele, que embarca a esposa grávida para a Itália com a guerra já iniciada, alegando desejar que o filho nasça lá; o ultimato da amante; o alistamento como voluntário no exército italiano "por culpa de una historia de amor mal resuelta” (PIGLIA, 2015a, p. 353), diz Ida.33 História heroica e infame ao mesmo tempo. Borges revisitado/degradado pela voz de Ida, a mãe:

Si me hice escritor, es decir, si tomé esa decisión que definió toda mi vida, fue también a causa de los relatos que circulaban en mi familia [...] Por eso a veces

33 “[...] por culpa de uma história mal resolvida" (PIGLIA, 2017, p. 373).

Remate de Males, Campinas-SP, v.39, n.2, pp. 586-6o9, jul./dez. 2019 - 606 
digo que le debo todo a mi madre, porque ella fue para mí el ejemplo más convincente del modo de ser de un narrador que dedica su vida a contar con variantes y desvíos siempre la misma historia (PIGLIA, 2015a, p. 341). ${ }^{34}$

\section{$\overline{\text { REFERENCIAS }}$}

BERG, Edgardo Horacio. Un fragmento recobrado en Los diarios de Emilio Renzi. In: Cuadernos LIRICO. [on-line]. Disponível em: <http:// journals.openedition.org/ lirico/7631>. Acesso em: 29 mar. 2019.

COZARINSKY, Edgardo. El relato indefendible. In: Nuevo museo del chisme. Buenos Aires: La Bestia Equilátera, 2013[1973], pp. 15-37.

GONZÁLEZ SAWCZUK, Susana Inés. Ricardo Piglia, Los diarios de Emilio Renzi, como figura especular de la lectura. In: FELIPPE, Eduardo Ferraz; PINTO, Júlio Pimentel (Orgs.). Só se perde o que realmente não se teve: leituras e diálogos com Ricardo Piglia. Rio de Janeiro: Metanoia, 2019, pp. 203-219.

KOHAN, Martín. Alter ego. Ricardo Piglia y Emilio Renzi: su diario personal. Revista Landa, v. 4, n. 2, 2017, pp. 261-272.

KOHAN, Martín. Diario diferido. In: Remate de Males, v. 39, n. 2, 2019, pp. 543-554

MESA GANCEDO, Daniel. La némesis literaria de Emilio Renzi en sus Diarios (de Ricardo Piglia). In: Cuadernos LIRICO. [on-line]. Disponível em: <http://journals. openedition.org/lirico/7934>. Acesso em: 23 mar. 2019.

MOLLOY, Silvia. Acto de presencia. La escritura autobiográfica en Hispanoamérica. México: Fondo de Cultura Económica, 1996.

ORECCHIA HAVAS, Teresa. Retratos ficcionales en la narrativa de Ricardo Piglia: variaciones sobre el retrato del (autor en) artista. Cuadernos LIRICO, n. 1, 2006, pp. 277-195. [Versão on-line, julho 2012]. Disponível em: <http://lirico.revues. org/820 >. Acesso em: 14 mar. 2019.

ORECCHIA HAVAS, Teresa. Máscaras del sujeto y mitos de origen del relato en la narrativa de Ricardo Piglia [2010]. Revista Landa, v. 5, n. 2, 2017, pp. 197-228.

ORECCHIA HAVAS, Teresa. El último viaje de Orfeo: Los diarios de Emilio Renzi. Cuadernos LIRICO. [on-line]. Disponível em: <http://journals.openedition.org/ lirico/7921>. Acesso em 18 mar. 2019.

34 "Se eu me tornei escritor, quer dizer, se tomei essa decisão que definiu toda a minha vida, foi também por causa dos casos que circulavam na minha família [...] Por isso às vezes digo que devo tudo à minha mãe, porque para mim ela foi o exemplo mais convincente do modo de ser de um narrador que dedica a vida a contar sempre a mesma história, com variantes e desvios." (PIGLIA, 2017, p. 359).

Remate de Males, Campinas-SP, v.39, n.2, pp. 586-609, jul./dez. 2019 - 607 
ROBERT, Marthe. Romance das origens, origens do romance. São Paulo: Cosac Naifiy, 2007[1973].

RODRÍGUEZ PÉRSICO, Adriana. De la literatura, el pudor y la verdad. Sobre Ricardo Piglia. Cuadernos LIRICO. [on-line]. Disponível em: <http://journals.openedition. org/lirico/7899>. Acesso em: 24/02/2019.

PIGLIA, Ricardo. Nombre falso. Buenos Aires: Siglo XXI, 1975.

PIGLIA, Ricardo. Nome falso. São Paulo: Iluminuras, 1988.

PIGLIA, Ricardo. Prisão perpétua. Trad. Sérgio Molina e Rubia Prates Goldoni. São Paulo: Iluminuras, 1989.

PIGLIA, Ricardo. Respiración artificial. Buenos Aires: Editorial Sudamericana, 1992[1980].

PIGLIA, Ricardo. A invasão. Trad. Rubia Prates Goldoni e Sergio Molina. São Paulo: Iluminuras, 1997.

PIGLIA, Ricardo. Primera persona. [Entrevista a Graciela Speranza]. In: Crítica y ficción. Buenos Aires: Seix Barral, 200oa[1992], pp. 143-154.

PIGLIA, Ricardo. Respiração artificial. Trad. Heloisa Jahn. São Paulo: Iluminuras, 2ooob.

PIGLIA, Ricardo. La invasión. Barcelona: Anagrama, 2006[1967].

PIGLIA, Ricardo. Prisión perpetua. Barcelona: Anagrama, 2007[1988].

PIGLIA, Ricardo. Los diarios de Emilio Renzi. Tomo I. Años de formación. Barcelona: Anagrama, 2015a.

PIGLIA, Ricardo. Los libros de mi vida. Páginas de una autobiografía futura. La Biblioteca. El arte de narrar. Variaciones sobre Ricardo Piglia, n. 15, 2015b, pp. 152-169.

PIGLIA, Ricardo. Roberto Arlt: una crítica de la economía literaria. La Biblioteca. El arte de narrar. Variaciones sobre Ricardo Piglia, n. 15, 2015c[1973], pp. 50-60.

PIGLIA, Ricardo. Los diarios de Emilio Renzi. Tomo II. Los años felices. Barcelona: Anagrama, 2016.

PIGLIA, Ricardo. Os diários de Emilio Renzi. Tomo I: Anos de formação. Trad. Sérgio Molina. São Paulo: Todavia, 2017.

PIGLIA, Ricardo. Os diários de Emilio Renzi. Tomo II: Os anos felizes. Trad. Sérgio Molina. São Paulo: Todavia, 2019.

PIGLIA, Ricardo. Ideología y ficción en Borges. In: BARRENECHEA et al. Borges y la crítica. Buenos Aires: Centro Editor de América Latina, 1979, pp. 87-95. 
PREMAT, Julio. Piglia: loco lector. In: Héroes sin atributos. Figuraciones de autor en la literatura argentina. Buenos Aires: Fondo de Cultura Económica, 2009, pp. 203-236.

PREMAT, Julio. Piglia/Renzi, postrero desliz. Cuadernos LIRICO. [on-line]. Disponível em: <http://journals.openedition.org/lirico/7907>. Acesso em: 6 mar. 2019.

SPERANZA, Graciela. Vida de lector. La Biblioteca. El arte de narrar. Variaciones sobre Ricardo Piglia, n. 15, 2015, pp. 288-297.

VILLORO, Juan. A arte de ler. Peixe elétrico, n. 1, 2015, pp. 26-32.

Recebido: 16/o8/2019

Aceito: 12/09/2019

Publicado: 25/11/2019

Remate de Males, Campinas-SP, v.39, n.2, pp. 586-6o9, jul./dez. 2019 - 609 